\title{
Rock forecast tool: new tool for rock mass quality prediction in tunnelling
}

\author{
A Tapia University of Concepción, and Concessionaire Tunnel El Melón, Chile \\ A Farías Pontifical Catholic University of Valparaíso, and Aura Ingeniería, Chile
}

\begin{abstract}
The tool presented in this article, known as rock forecast tool (RFT), is based on the quantitative interpretation of the geological characteristics obtained from the drilling of exploratory drill holes towards the unexcavated zone of tunnels under construction. This correlates the drilling results with rock quality values that have been previously calculated on the advanced faces. The results provided by this new tool are numerical values of rock mass quality in each of the drill rods used in exploratory drilling.

The results obtained by the RFT have been subjected to different statistical tests such as the Pearson's correlation coefficient, $R$ hypothesis test, confidence intervals and covariance test. All the tests carried out show that the RFT, used as a predictor, has a high correlation with the rock mass quality values that are subsequently calculated in the excavated sections, with an $R^{2}=0.95$.
\end{abstract}

Keywords: tunnelling, rock mass quality, prediction, exploratory drilling

\section{$1 \quad$ Introduction}

In civil and mining tunnel construction works, different tools and methodologies are currently used to evaluate the quality of the rock mass. The geological and geotechnical evaluations carried out within the construction cycle allow the user to indicate the rock quality and define the necessary ground support and reinforcement through the NGI-Q (Norwegian Geotechnical Institute 2015), rock mass rating (RMR) (Bieniawski 1989) and geological strength index (Hoek \& Brown 2018) systems.

This paper demonstrates the application of the principles of rock mass characterisation to volumes of rock that cannot otherwise be observed with traditional approaches, by using the rock forecast tool (RFT).

The RFT model can be defined as a data interpretation tool that gives a standard value formed by the sum of measurable characteristics extracted from exploratory boreholes. It has proved to be very useful in proactive decision-making regarding ground support and reinforcement selection.

The RFT has undergone long improvement and optimisation developments in various underground constructions in Chile, evolving from a qualitative conceptualisation to the development of a numerical model capable of being correlated with the geomechanical classification systems.

The RFT model presented in this paper manages to deliver rock mass quality values quickly along sections evaluated by exploratory drilling and allows, with a high level of confidence, timely constructive decisions to be made in heterogeneous geological environments, with or without the presence of water.

\section{Construction of the rock forecast tool model}

The RFT model takes data from exploratory drillings in each of the rods used for its execution and emphasises the geological characteristics of the recovered chips, the water that returns from the drilling, and the stability of the drill rods at the time of execution.

The exploratory boreholes are made in the tunnel face by a jumbo drilling machine using a destructive bit. The length of each rod can vary depending of the project requirements and the jumbo drilling machine itself 
and are commonly between 2.4 to $4.0 \mathrm{~m}$ in length. The total length of an exploratory hole is defined using double criteria:

1. The time invested in an exploratory borehole has an impact in the construction cycle. A single borehole of $20 \mathrm{~m}$ depth takes approximately one hour with a jumbo machine such as Boomer 282 or Sandvik DT-1331.

2. The drill bit technology selected has an impact in the hole deviation. A conventional Tophammer T45/51 may suffer $3 \mathrm{~m}$ of deviation at the bottom of a $30 \mathrm{~m}$ deep hole. Although the Retractable Tophammer with guide rod may have $1.5 \mathrm{~m}$ of deviation at the same depth, the Down the Hole COPROD bit has insignificant deviation.

Taking these two variables into account, it is reasonable to execute boreholes of 20-25 m depth. Figure 1 shows a scheme of the three types of bits.

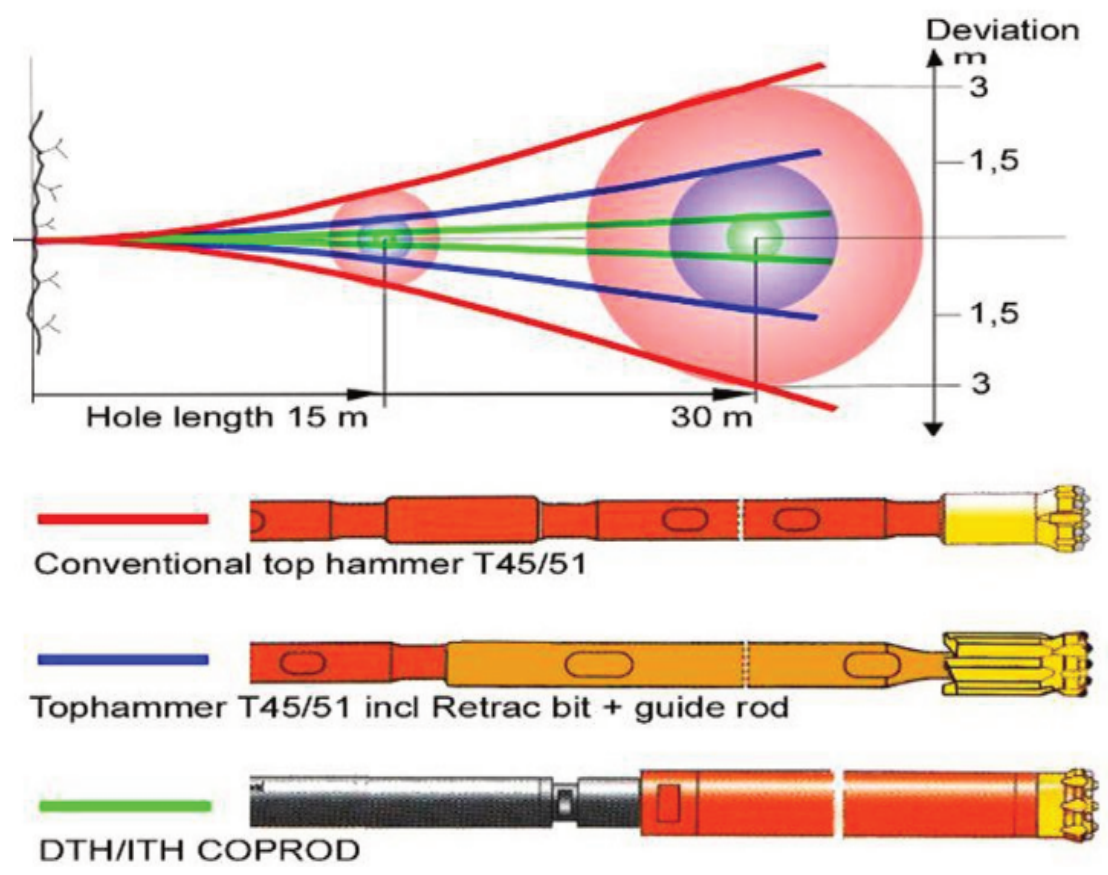

Figure 1 Typical deviations in different types of drill bits (Oraee et al. 2014)

In the execution of an exploratory drilling, the first step is to record qualitative and quantitative characteristics in every drilled rod. At the end of drilling using each rod, the sample is returned and analysed for the following parameterised characteristics (highlighted in bold font the parameters used in RFT model):

1. Identification of the drilled length.

2. Effective drilling time.

3. Drilling speed.

4. Drilling stability.

5. Drilling water colour.

6. Identification of water inlets from the rock mass and allocation of groundwater.

7. Size of the rock chips recovered.

8. Dominant minerals and lithological type.

9. Degree of weathering and alteration in lithology. 
Of the set of parameters used in the exploratory drilling register, the RFT model uses six of them and assigns a standardised score to each one. The sum of the normalised values of the variables takes the form of the following equation:

$$
\begin{gathered}
R F T=(1)+(2)+(3)+(4)+(5)+(6) \\
{[5 \leq R F T \leq 100]}
\end{gathered}
$$

where:

(1) = rod's steadiness in active drilling.

(2) $=$ colour of the drilling water.

(3) = natural water flow (litres per second, $\mathrm{l} / \mathrm{s}$ ).

(4) = size of drilled rock chips ( $\mathrm{mm}$ ).

(5) = percentage of minerals or rock fragments.

(6) = degree of alteration (hydrothermal, epithermal, metasomatic or metamorphic phases with formation of silica and/or minerals with a high degree of resistance). Degree of weathering (primary rock minerals transformed to oxides, hydroxides and salts).

The details of each factor are presented further in this section. Parameter number six has been grouped together taking into account weathering condition of lithology and alteration condition of lithology.

The necessary staff needed to collect the information to build the RFT model is composed by one drill operator and a geologist.

The register sheet used to capture the global parameters-including the factors to build the RFT model-is shown in Figure 2.
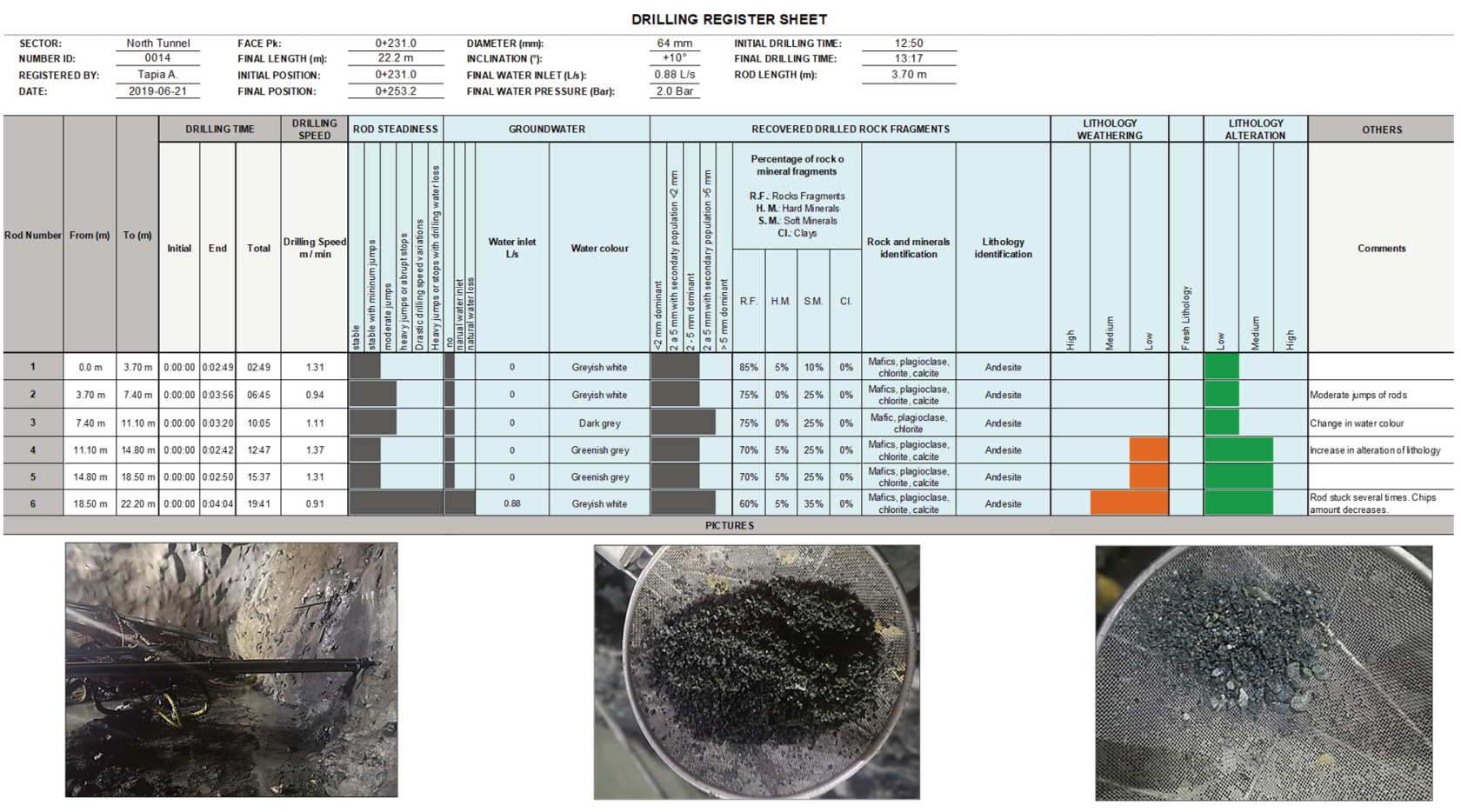

Figure 2 Exploratory drilling register. The parameters for the rock forecast tool model construction are shown in blue

The lowest value reached was 5 and this indicates the presence of a rock mass with an extremely high degree of oxidation and/or alteration, with abundant poly-directional structures of the 'sugar cube' type, open, with 
soft low friction infillings, with transmission of water under considerable pressure, and high degree of weathering.

The highest value reached was 100 and this indicates the presence of a fresh rock mass, without weathering, but with considerable siliceous alteration, dry, with few structures that have healthy walls, without an observable degree of anisotropy, and without clays.

Figure 3 shows and example of two types of rock quality assessments using the RFT model. Figure 3a shows highly weathered conditions with mechanical excavation, buttress construction, and heavy ground support composed of steel bars and shotcrete. Figure $3 \mathrm{~b}$ shows excavation with good rock quality conditions, unweathered lithology, and good blasting contour.

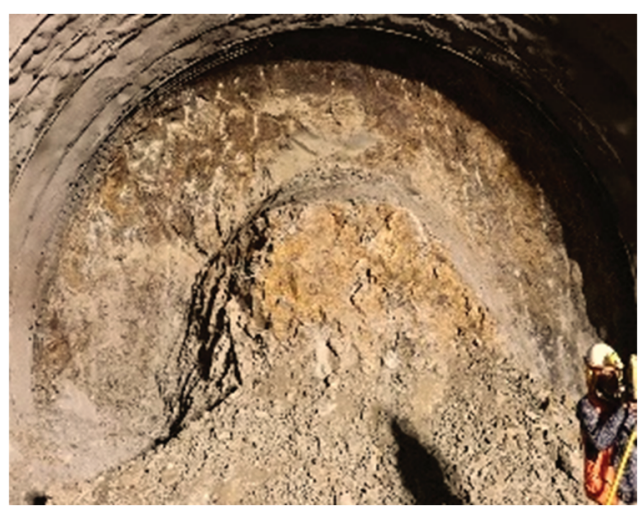

(a)

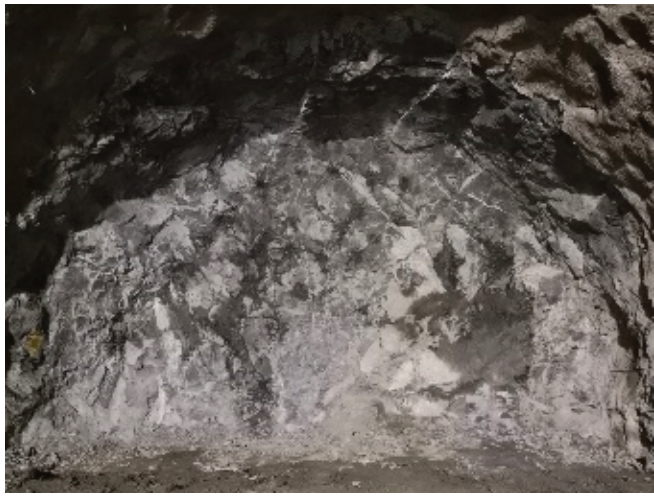

(b)

Figure 3 (a) Tunnel excavation with evaluation RFT = 26; (b) Tunnel excavation with evaluation RFT = 79

\subsection{Drilling rods steadiness}

The rod steadiness parameter is used to correlate the fracture state of the rock mass. A rock mass with a high level of fracturing that has mineralogical fillings with a low friction angle, causes a discontinuous drilling with abrupt jumps of the drill rods. In the extreme cases, there is a loss of drilling water due to encountering areas with cavities. Conversely, an isotropic rock mass with low or no fracturing allows for continuous drilling with no jump in the drill rods. The steadiness assessment is made with the observations made by driller operator and the geologist in charge to collect the samples. It is believing of the authors of this paper that the record of this parameter can be improved with the use of vibration and noise sensors fitted to the drill machine.

Table 1 introduces the entire evaluation spectrum for the rod steadiness parameter used for the RFT modelling.

\section{Table 1 Rock forecast tool rod steadiness parameter evaluation}

\begin{tabular}{|c|c|c|c|c|c|}
\hline \multicolumn{6}{|c|}{ Parameter (1): Rod drill steadiness } \\
\hline (a) & (b) & (c) & (d) & (e) & (f) \\
\hline $\begin{array}{l}\text { Stable } \\
\text { rod }\end{array}$ & $\begin{array}{l}\text { Rod with } \\
\text { minimum } \\
\text { jumps }\end{array}$ & $\begin{array}{l}\text { Rod with } \\
\text { continuous } \\
\text { jumps }\end{array}$ & $\begin{array}{l}\text { Rod with abrupt } \\
\text { jumps }\end{array}$ & $\begin{array}{l}\text { Suddenly increase of } \\
\text { penetration, partial stops } \\
\text { and/or loss of water }\end{array}$ & $\begin{array}{l}\text { Rotation } \\
\text { loss, loss of } \\
\text { drilling water }\end{array}$ \\
\hline \multicolumn{6}{|c|}{ Rating for rock forecast tool model } \\
\hline 17 & 12 & 9 & 6 & 3 & 1 \\
\hline
\end{tabular}

\subsection{Drilling water colour}

The drilling of exploratory holes requires the injection of water to cool the drilling bit, which returns through the collar of the hole. The finest drilling cuttings mix with the drilling water, giving a distinctive colour as it 
returns through the drill collar. Thus, when the borehole passes through areas of fresh rock, the drilling water returns with a colour similar to intact rock, whereas when the drilling passes through areas with structures rich in iron oxides, the water returns with an orange hue and if it passes through areas rich in clay, the water acquires a white-yellow hue to a light-yellow colour. In extreme cases of the presence of clays, the return water noticeably changes its density and viscosity, as well as its colour.

The register of this parameter is made by the geologist in charge of the logging. Table 2 introduces the evaluation of this parameter including the rating to be made in every rod.

\section{Table 2 Rock forecast tool drilling water colour parameter evaluation}

\begin{tabular}{|c|c|c|c|c|c|}
\hline \multicolumn{6}{|c|}{ Parameter (2): Drilling water colour } \\
\hline (a) & (b) & (c) & (d) & (e) & (f) \\
\hline White & Grey & $\begin{array}{l}\text { Grey with hue } \\
\text { beige, orange or } \\
\text { green }\end{array}$ & $\begin{array}{l}\text { Brown with } \\
\text { hue beige }\end{array}$ & $\begin{array}{l}\text { Yellowish } \\
\text { white }\end{array}$ & Yellow \\
\hline $\begin{array}{l}\text { Silica like } \\
\text { mineral }\end{array}$ & $\begin{array}{l}\text { From } \\
\text { dominant } \\
\text { rock } \\
\text { chips }\end{array}$ & $\begin{array}{l}\text { From oxides, } \\
\text { chlorite and soft } \\
\text { mineral infillings } \\
\text { in water }\end{array}$ & $\begin{array}{l}\text { From low clay } \\
\text { presence }\end{array}$ & $\begin{array}{l}\text { From medium } \\
\text { clay presence }\end{array}$ & $\begin{array}{l}\text { From high } \\
\text { clay } \\
\text { presence }\end{array}$ \\
\hline \multicolumn{6}{|c|}{ Rating for rock forecast tool model } \\
\hline 17 & 13 & 9 & 6 & 3 & 0 \\
\hline
\end{tabular}

Each of the elements that make up the parameter is assigned a value. In Figure 4, examples of the evaluation spectrum are shown. In Figure 4a, the cooling water returns with white hue while drilling an andesite with siliceous alteration (type a, Table 2). In Figure $4 b$, the cooling water returns grey with beige-green hue while drilling a granodiorite with thin structures filled with oxides and chlorite (type c, Table 2). In Figure 4c, the cooling water returns beige with yellow hue while drilling an andesite with structures filled with calcite and clay (type d, Table 2).

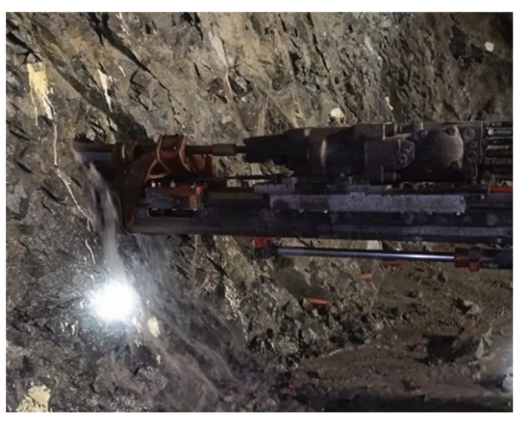

(a)

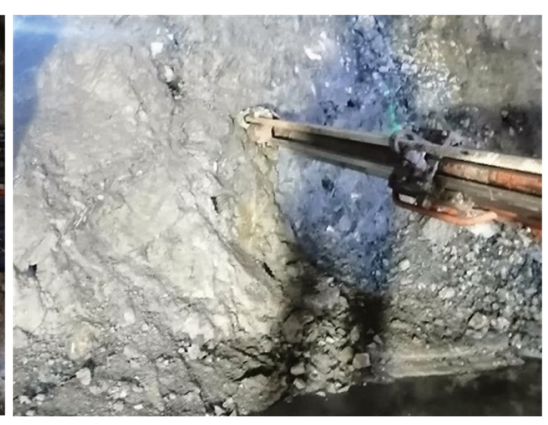

(b)

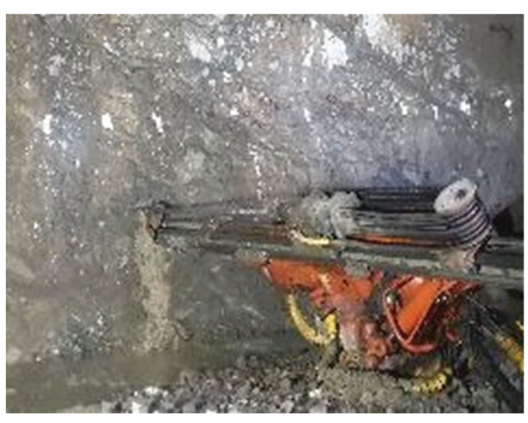

(c)

Figure 4 Drilling water colour evaluation: (a) Water colour white; (b) Water colour grey with beige-green hue; (c) Water colour beige with yellow hue

\subsection{Groundwater inflow}

This parameter evaluates the encounter of the borehole with groundwater. When the borehole encounters structures that transmit groundwater, as a rule, the rods shake with small abrupt jumps and an increase in the return water flow can be observed. 
The professional evaluator can, at that moment, stop the drilling when the rod change occurs and measure the natural water flow. It is also worthwhile to measure the flow and pressure at the end of the drilling if the rod that intersected the infiltration of natural water is clearly identified.

The measurements carried out for the present study indicate that the flow rates measured at the end of the drillings that are less than $1.0 \mathrm{l} / \mathrm{s}$ and with a pressure less than $2.0 \mathrm{bar}(200 \mathrm{kPa})$, do not affect the quality of the rock mass due to the scale effect between the drilling and excavation.

The most unfavourable case is constituted by the manifestation of water with flow rates greater than $2.5 \mathrm{l} / \mathrm{s}$ and with a pressure of $2.0 \mathrm{bar}(200 \mathrm{kPa})$ or more.

Table 3 introduces the evaluation of this parameter including the rating to be made in every rod.

Table 3 Rock forecast tool groundwater inflow parameter evaluation

\begin{tabular}{lllll}
\hline \multicolumn{5}{l}{ Parameter (3): Groundwater inflow } \\
\hline & (a) & (b) & (c) & (d) \\
\hline Inflow (I/s) & $0-1.0$ & $1.0-2.5$ & $1.0-2.5$ & $>2.5$ \\
Pressure (bar) & $<2.0$ & $<2.0$ & $>2.0$ & $>2.0$ \\
\hline \multicolumn{5}{c}{} \\
\hline & Rating for rock forecast tool model \\
\hline & 17 & 13 & 8 & 4 \\
\hline
\end{tabular}

Figure 5 shows groundwater inflow draining from an exploratory drilling collar with inflow of $1.0 \mathrm{l} / \mathrm{s}$ and pressure 0.5 bar $(50 \mathrm{kPa})$. Final water inflow and pressure can be measured with the help of a mechanical packer connected to a pressure gauge.

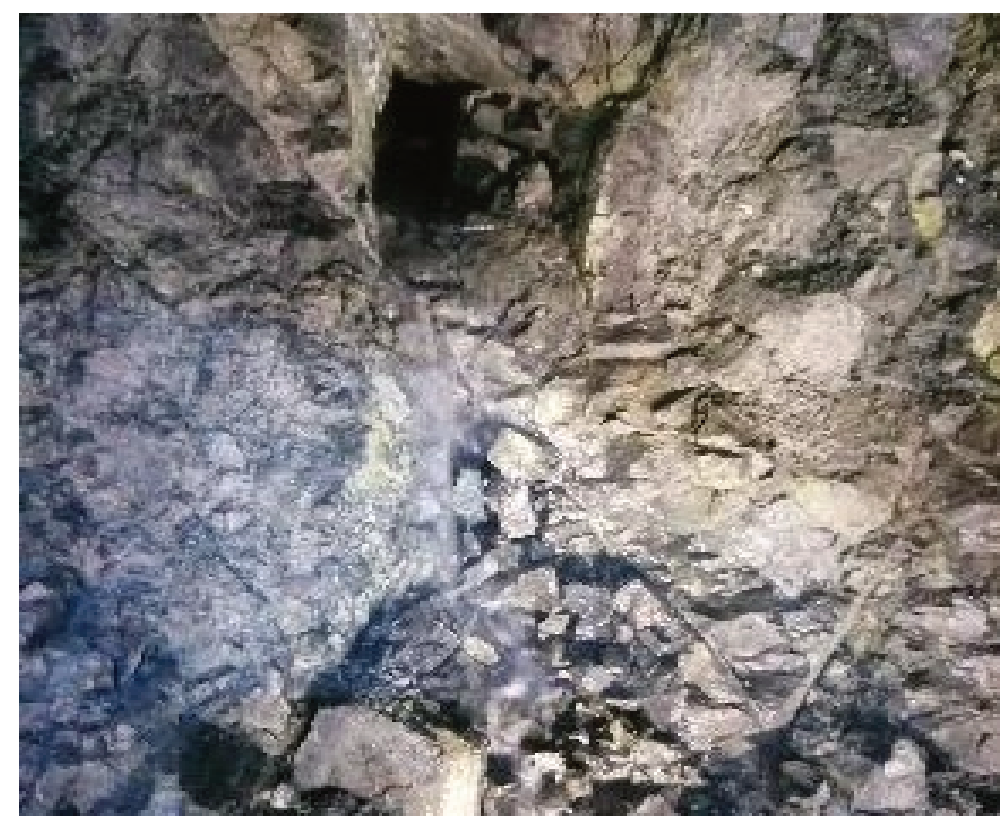

Figure 5 Completion of exploratory drilling with the presence of groundwater with a flow rate of $1.0 \mathrm{l} / \mathrm{s}$ and pressure of $0.5 \mathrm{bar}(50 \mathrm{kPa})$

\subsection{Chips sizes}

During the development of the RFT model, the numerical results showed a correlation between the size of the chips from the drilled rock with the uniaxial compressive strength (UCS) of the intact rock (UCS and grades according to Hoek \& Brown 1980b). Furthermore, in tunnel excavation, different UCS values from different 
lithologies, including faults zones, will impact the tunnel construction in an anisotropic way (Hoek \& Brown 1980a).

The surprise was that the correlation between the chip sizes and UCS has an inverse character. In other words, rock types with high UCS R5-R6 in crushed state have a high population of chips sizes below $2.0 \mathrm{~mm}$. The chip size increases while the UCS decreases until it reaches the limit of UCS $=R 2(5-25 \mathrm{MPa})$.

For rock types with UCS R0 and R1 (below $5 \mathrm{MPa}$ ), the chip size is clearly smaller than $2.0 \mathrm{~mm}$, forming a muddy/clayey mass. In this case, it is important that the geologist evaluate this special type with lower value in the parameter rating.

Having said this, the chip size parameter represents the degree of strength of the intact rock and the hardness of the minerals present in the structures.

For its evaluation, it is necessary to recover the chips with a strainer and correctly identify the drilling depth. A good practice is to use a labelling and storage system, such as chip trays, as used in reverse air drillings for later in-cabinet analysis such as high-resolution photography.

The data analysed for the present study have shown that the relationship between the size of the chips is inversely proportional to the degree of resistance of the rock. That is, rocks with high strength and hard minerals will generate chips with a smaller size than chips of rocks with low resistance and soft minerals.

As a rule of thumb, a fresh rock will deliver a chip with a uniform size of 2.0 to $5.0 \mathrm{~mm}$ in maximum length. A rock that exhibits weathering will deliver a chip larger than $5 \mathrm{~mm}$, while, at the opposite extreme, an extremely resistant rock that has advanced siliceous alteration tends to deliver an observable and relevant population of chips less than $2 \mathrm{~mm}$ thick size.

The parameter also considers the representation of a homogeneous chip size and those with a polymodal population.

Table 4 introduces the evaluation of this parameter, including the rating to be made in every rod. Rating is valid for rock types with UCS equal or higher than R2 (UCS and grades according to Hoek \& Brown 1980b). If the high-resolution photography analysis and other empirical evaluation indicates the presence of rock types with UCS lower than R2, the lowest value should be selected.

Table 4 Rock forecast tool chips sizes parameter evaluation

\section{Parameter (4): Chips sizes}

\begin{tabular}{lllll}
\hline $\begin{array}{l}\text { (a) } \\
<2.0 \mathrm{~mm}\end{array}$ & (b) & (c) & (d) & (e) \\
dominant & $\begin{array}{l}2.0 \text { to } 5.0 \mathrm{~mm} \\
\text { secondary population of } \\
\text { chips }<2 \mathrm{~mm}\end{array}$ & $\begin{array}{l}2.0 \text { to } 5.0 \\
\text { mm uniform }\end{array}$ & $\begin{array}{l}2.0 \text { to } 5.0 \mathrm{~mm} \\
\text { secondary population } \\
\text { of chips }>5 \mathrm{~mm}\end{array}$ & $\begin{array}{l}>5.0 \mathrm{~mm} \\
\text { dominant }\end{array}$ \\
\hline \multicolumn{5}{c}{ Rating for rock forecast tool model } \\
\hline 17 & 11 & 8 & 4 & 1 \\
\hline
\end{tabular}

Figure 6 shows the different phases of analysis and storage from a single exploratory borehole. Figure $6 a$ shows the chips recovery in bags directly in the field. A good practice is to recover two bags per rod. In this step, the geologist can quickly assess the colour of the chips, main sizes, presence of clays or other minerals from lithology and structures. Figure $6 \mathrm{~b}$ shows analysis made back in the office, where the samples are put into storage plastic boxes. Figure $6 \mathrm{c}$ shows the storage system from three different boreholes. 


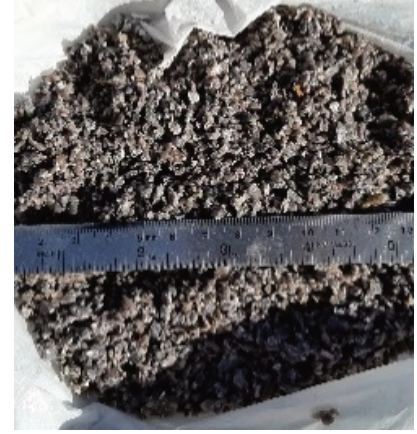

(a)

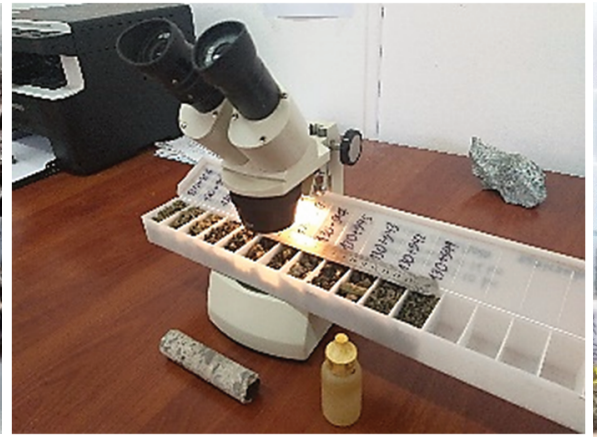

(b)

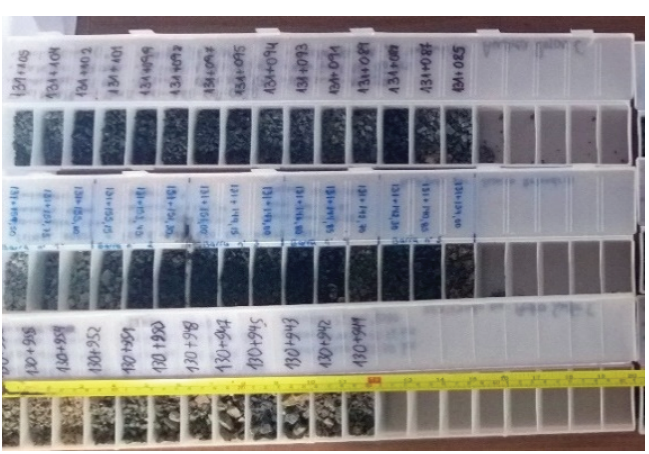

(c)

Figure 6 Rock chip recovery and subsequent cabinet analysis. (a) Chips recovery from field; (b) Size analysis with magnifying glass; (c) Chips storage system

\subsection{Chips lithology and mineralogy}

This parameter allows you to establish the existing correlation between the mineralogy of the chips with the state of structural friction of the rock mass. The identification of minerals with high hardness, such as quartz, epidote, feldspars, and primary metallic minerals, constitutes proof of the existence of structures that have high resistance and friction angle and vice versa, and the presence of soft minerals provides evidence of structures with low resistance and low friction angle.

The highest end of this classification is represented by the joint presence of highly dominant hard minerals in percentage together with rock fragments in the same state. The lower end of the classification corresponds to the presence of weathered soft minerals with a high presence of clays in conjunction with rock fragments under the same conditions.

As can be seen in Figure 6, it is possible to make a quantitative interpretation of the change shown by the recovered chips, both due to their size and their lithological and mineralogical characteristics.

Table 5 introduces the evaluation of this parameter including the rating to be made in every rod.

Table 5 Rock forecast tool chips mineralogy and lithology parameter evaluation

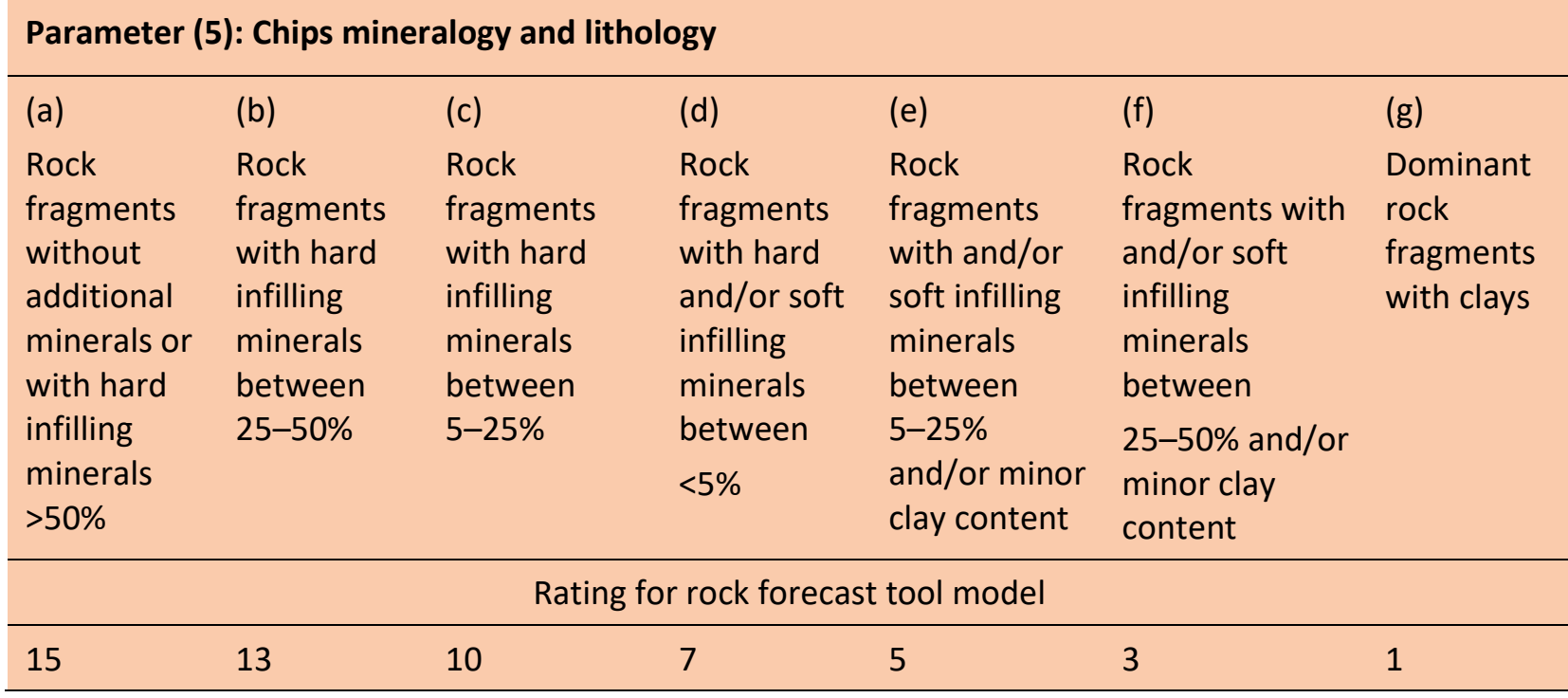

\subsection{Degree of alteration and/or weathering}

The sixth and last parameter that completes the generation of the RFT model focusses on the identification of the degree of alteration and weathering that the chips recovered from rock possess. 
The definition of alteration accepted for the generation of the RFT model corresponds to the identification of changes in the original mineralogy of the rock, as a result of hydrothermal events, metasomatism and contact aureoles that generate a gain in the resistance properties of the intact rock, e.g. a silicification that causes an increase in the quartz content. Any other type of transformation process or mineralogical exchange that leads to a loss of strength of the intact rock, such as a massive clay formation, is incorporated into the weathering zone.

The definition of weathering is the generation of changes in the rock due to physical and chemical surface actions, where agents such as water intervene and create minerals with a higher oxidation state at the expense of the original minerals of the rocks. Increased weathering brings with it a loss in the strength properties of intact rock and the strength properties of rock mass structures.

Table 6 introduces the evaluation of this parameter including the rating to be made in every rod.

Table 6 Rock forecast tool degree of alteration/weathering parameter evaluation

\begin{tabular}{|c|c|c|c|c|c|c|}
\hline \multicolumn{7}{|c|}{ Parameter (6): Degree of alteration/weathering } \\
\hline \multicolumn{3}{|c|}{ Degrees of alteration } & \multicolumn{2}{|l|}{ Fresh } & \multicolumn{2}{|c|}{ Degrees of weathering } \\
\hline (a) & (b) & (c) & (d) & (e) & (f) & (g) \\
\hline High & Medium & Low & & Low & Medium & Fresh \\
\hline $\begin{array}{l}\text { Hard } \\
\text { infilling } \\
\text { alteration } \\
\text { minerals }\end{array}$ & $\begin{array}{l}\text { Hard } \\
\text { infilling } \\
\text { alteration } \\
\text { minerals }\end{array}$ & $\begin{array}{l}\text { Hard } \\
\text { infilling } \\
\text { alteration } \\
\text { minerals }\end{array}$ & $\begin{array}{l}\text { Fresh } \\
\text { rock }\end{array}$ & $\begin{array}{l}\text { Soft infilling } \\
\text { weathering } \\
\text { minerals } \\
\text { Oxides, } \\
\text { chlorite, clays }\end{array}$ & $\begin{array}{l}\text { Soft infilling } \\
\text { weathering } \\
\text { minerals } \\
\text { Oxides, chlorite, } \\
\text { clays }\end{array}$ & $\begin{array}{l}\text { Soft infilling } \\
\text { weathering minerals } \\
\text { Oxides, chlorite, } \\
\text { clays }\end{array}$ \\
\hline$>50 \%$ & $25-50 \%$ & $5-25 \%$ & & $5-25 \%$ & $25-50 \%$ & $>50 \%$ \\
\hline \multicolumn{7}{|c|}{ Rating for rock forecast tool model } \\
\hline 17 & 15 & 12 & 9 & 6 & 3 & 1 \\
\hline
\end{tabular}

\section{Case study: New El Melón Tunnel II}

The El Melón II New Tunnel Project (TEM-II) corresponds to the phase of road infrastructure improvement of the main highway in Chile and is located in the $\mathrm{V}$ Region of Valparaíso.

The project consists of a $2.8 \mathrm{~km}$-long tunnel, crown slopes at the portals of the new tunnel, and expansion of the existing road route. Construction of the tunnel began in February 2019 and was completed in May 2020. The tunnel construction was made by Aura Ingeniería Company.

There are plans to expand the actual tunnel El Melón I, improve its infrastructure, and excavate five connecting tunnels between the two-four pedestrian and one vehicular as an emergency exit.

Figure 7 shows the location of the project. Figure 7.a is the regional picture showing the location of the project in red rectangle. Figure 7b shows the New Tunnel El Melón II in blue line. 


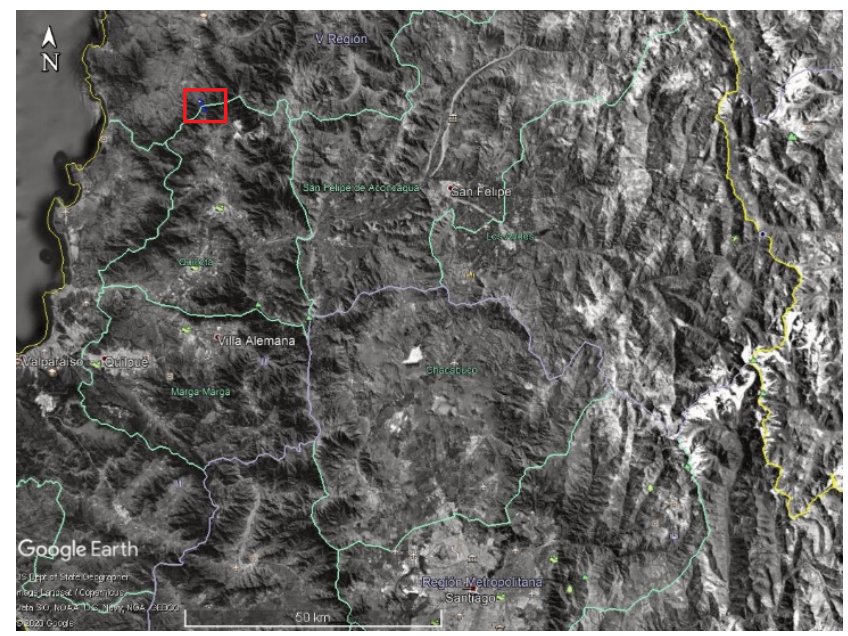

(a)

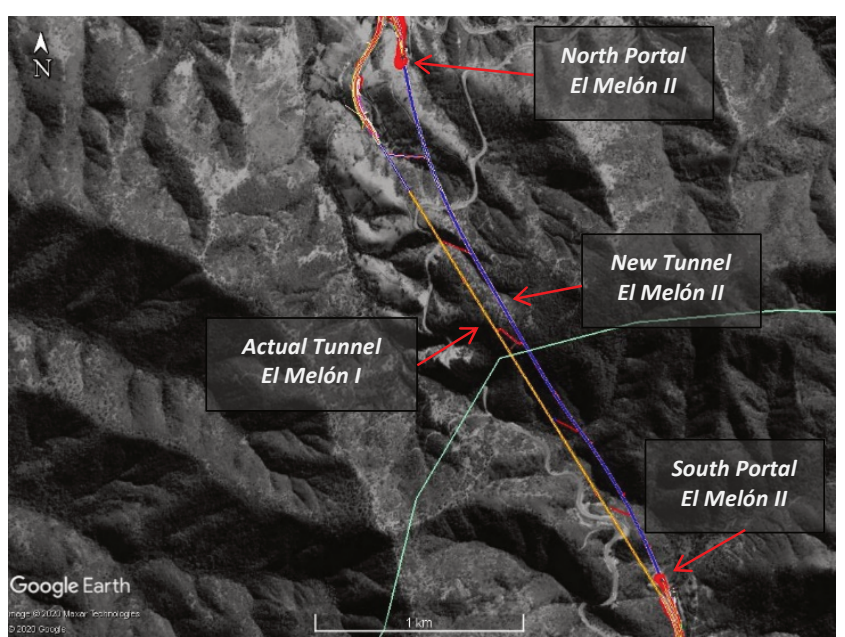

(b)

Figure 7 Location of the El Melón II Tunnel Project; (a) Regional image with the project El Melón II highlighted in red rectangle; (b) New tunnel drawn in blue (Google Earth 2020)

\subsection{New tunnel dimensions and support characteristics}

The TEM-II Project main tunnel has excavation dimensions of $11.08 \mathrm{~m}$ wide $\times 7.73 \mathrm{~m}$ high in the shape of a horseshoe tunnel. These dimensions will allow the transit of vehicles on two axes.

The ground support and reinforcement defined in the detailed engineering is based on the classification of the NGI-Q system (Norwegian Geotechnical Institute 2015), and is made up of five rock classes, which, according to the base studies, are distributed as shown in Figure 8.

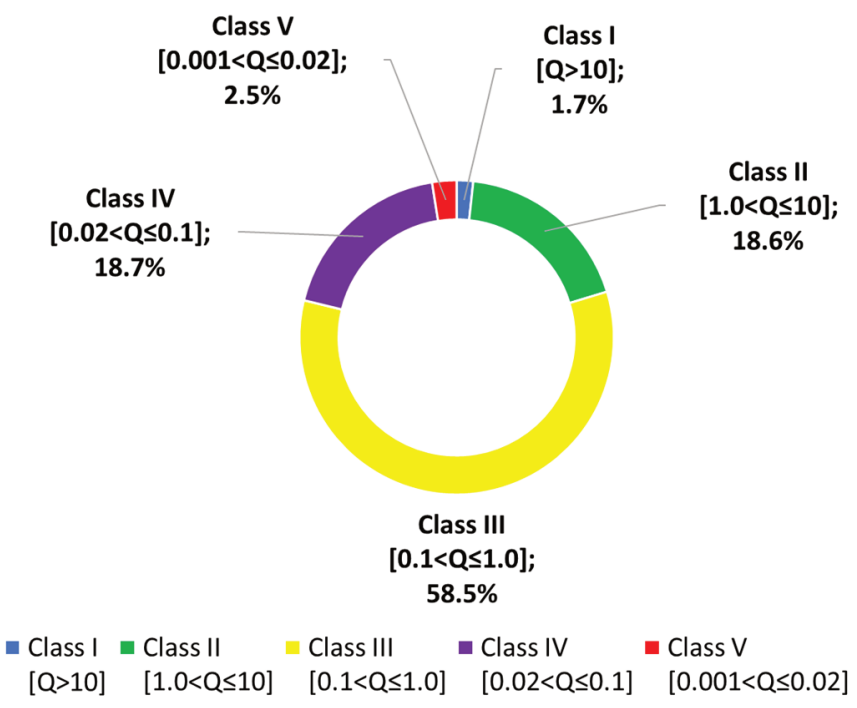

\begin{tabular}{ll}
\hline Rock mass classes NGI-Q (Norwegian Geotechnical Institute 2015) \\
\hline Class I & Greater than good \\
Class II & Poor and fair \\
Class III & Very poor \\
Class IV & Extremely poor \\
Class V & Exceptionally poor and extremely poor \\
\hline
\end{tabular}

Figure 8 Distribution of rock classes in detail engineering, El Melón II New Tunnel Project 


\subsection{New tunnel excavation method}

The TEM-II tunnel, which is already fully excavated, was built using the drilling and blasting methodology using state-of-the-art machinery in the industry consisting of Putzmeister SPM 4210 shotcrete spraying equipment, JCB 367-ZX side dump loaders, $20 \mathrm{~m}^{3}$ capacity hopper trucks, and two Sandvik DT1130 and DT1131 electro-hydraulic three-arm jumbo units. Two technologies were tested for blasting: ANFO and bulk emulsion.

Figure 9 shows part of the critical equipment used in the tunnel construction. Figure 9a shows JCB 367-ZX side dump loader and Figure 9b shows Jumbo Sandvik DT1130 in Rockbolt drilling operation.

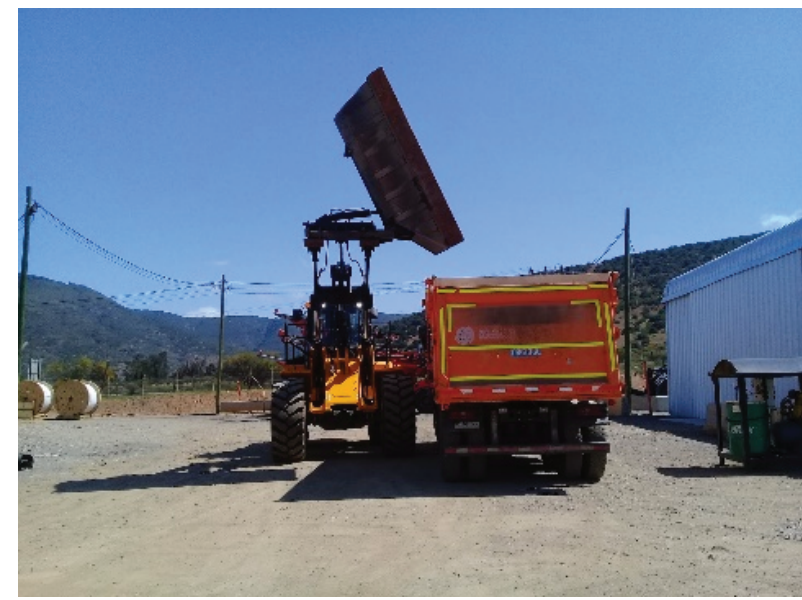

(a)

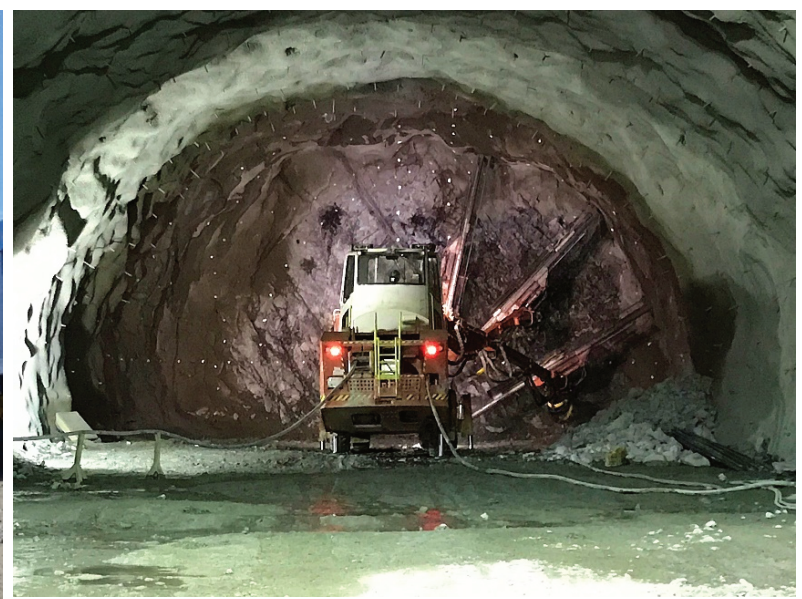

(b)

Figure 9 (a) Loading activity with a side dump loader; (b) Simultaneous drilling with three arms for support, Project TEM-II

\subsection{Geology of El Melón II Project}

The project is in stratified volcanic and volcanoclastic rocks of the Ajial Formation, of Jurassic age and intrusive rocks, mainly granodiorites, and of Cretaceous or Lower Tertiary age (Rivano 1993).

Some sectors present hydrothermal alteration associated with late-magmatic intrusive phenomena and shear zones or deep faults (Tunnel El Melón II 2018).

From the point of view of structural geology, there are three types of structures that have cut and fractured the rocks directly or indirectly. These are regional fault zones, local faults, and joint systems. The preferential orientations of the local structures range between a strike/dip of $N 10^{\circ}-35^{\circ} \mathrm{W} / 60^{\circ} \mathrm{SW}$ and the secondary structures with strike/dip between $\mathrm{EW}-\mathrm{N} 75^{\circ} \mathrm{E} / 80^{\circ} \mathrm{S}$. The first is subparallel to the tunnel and corresponds to the most unfavourable orientation (Tunnel El Melón II 2018).

The geological faults with the greatest impact on the TEM-II Project were identified in a total of 18 sectors along the tunnel's route, based on the information available from the construction of El Melón I Tunnel, core analysis from diamond drill holes, and geomechanical windows.

Figure 10 correspond to the geological profile of El Melón Tunnel. 


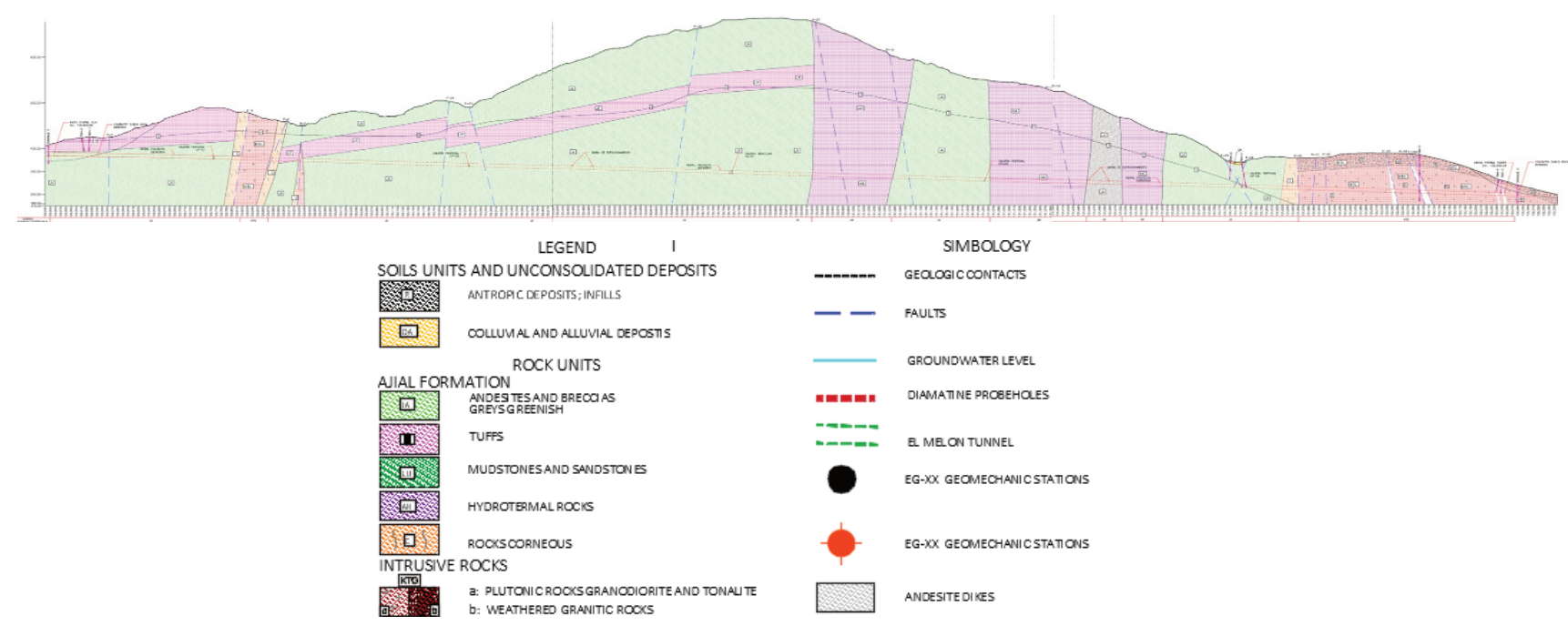

Figure 10 Geological profile El Melón II New Tunnel Project

\subsection{Execution of exploratory drilling and rock forecast tool model results}

The TEM-II Project incorporated the systematic drilling of exploratory boreholes, carried out using Sandvik electro-hydraulic jumbo rigs (models DT1130 and DT1131), into its excavation cycle. The three arms of each rig were equipped with $25 \mathrm{~kW}$ hydraulic drills, capable of reaching a percussion pressure of $220 \mathrm{bar}(22 \mathrm{MPa})$ and a rotation speed of 280 revolutions per minute.

The exploratory holes were drilled with a diameter of $64 \mathrm{~mm}$ and a length range between $20-27 \mathrm{~m}$. The rods used in exploratory drilling have a length of $3.0 \mathrm{~m}$. The geology staff of the construction team oversaw the supervision of each drilling, data collection, and samples for later analysis.

The architecture of the RFT was made in a way that allowed the delivery of a standard value for each drill rod. Thus, each borehole was able to deliver between six to nine RFT values every $3.0 \mathrm{~m}$ of drilling.

Figure 11 shows the RFT results in all the exploratory boreholes carried out (red points), contrasted with the subsequent rock quality evaluations using NGI-Q system (blue points). The graph shows a synchronous correspondence between the behaviours of the RFT model with the variations presented by the values calculated using Barton's Q. Likewise, low RFT values show low Barton $Q$ values and, conversely, high RFT values show high Barton $Q$ values.

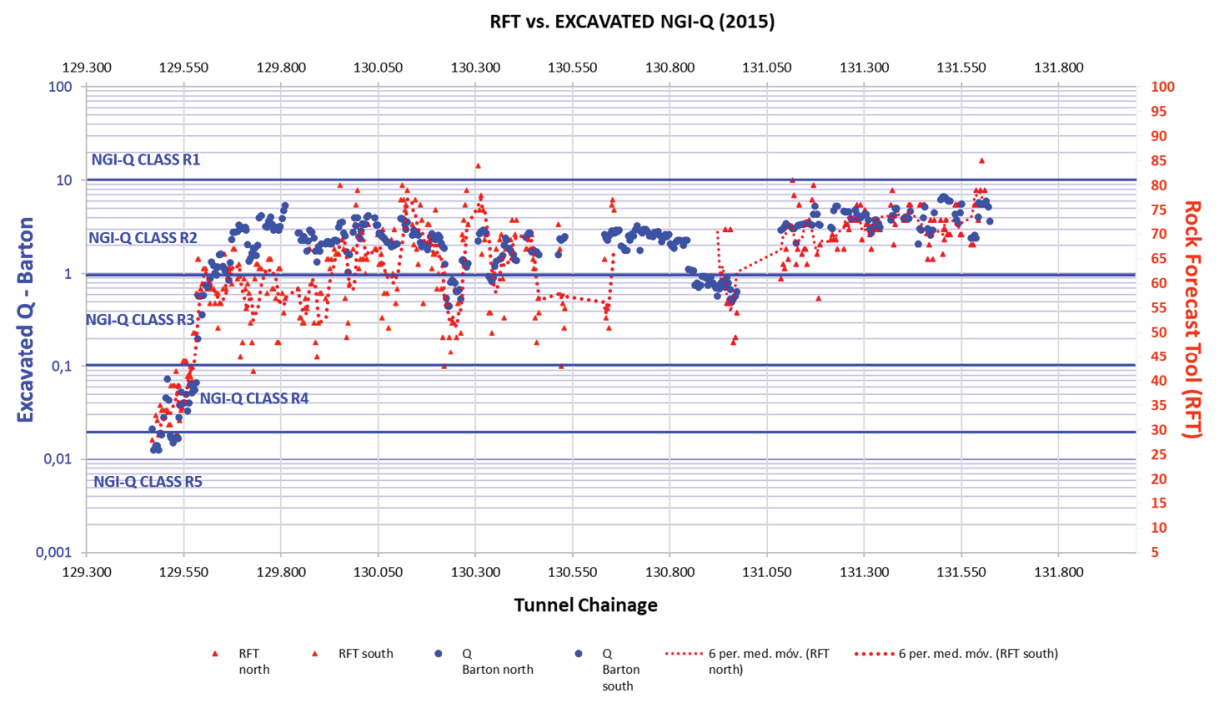

Figure 11 Numerical correspondence in rock forecast tool model and NGI-Q values. The classes shown correspond to the NGI-Q system used in the project TEM-II 
Figure 12 shows the correlation between the values of the RFT model with the NGI-Q (Norwegian Geotechnical Institute 2015) values obtained in the subsequent evaluations carried out in the tunnel excavation, from which is possible to extract several antecedents:

1. The existing correlation is positive, represented by the blue correlation line.

2. The correlation formula is represented by:

$$
R F T=6.67 \times \operatorname{Ln}\left(Q_{B A R T O N}\right)+60
$$

3. If a variation of \pm 10 points to the RFT values is considered, the correlation incorporates $95 \%$ of the correlation data. This condition is reflected in the segmented lines of Figure 12.

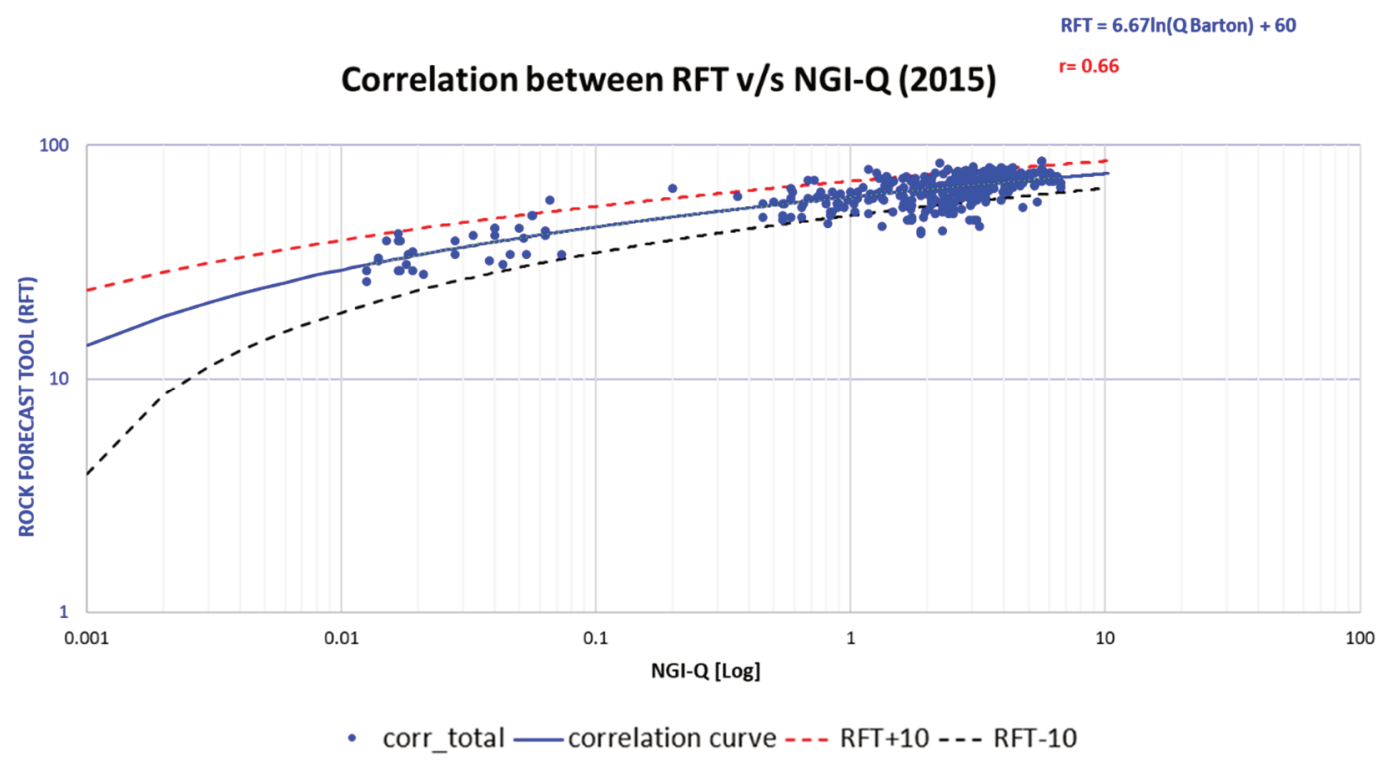

Figure 12 Correlation graph between rock forecast tool model and NGI-Q

To test the strength of the correlation shown, the RFT model has been subjected to different statistical tests, which are shown as follows.

\section{$4 \quad$ Statistical validation tests of rock forecast tool model}

The statistical evaluation carried out on the numerical results obtained through the RFT model includes the following statistical tests (Cohen \& Cohen 1983; Pedhazur 1997):

1. Covariance statistic.

2. Pearson's correlation coefficient ( $r$ ).

3. Hypothesis test of $r$.

4. Confidence interval of the correlation coefficient.

\subsection{Covariance statistic}

The existence of a positive association $\left(S_{X Y}>0\right)$, negative $\left(S_{X Y}<0\right)$, or non-existent association $\left(S_{X Y}=0\right)$ will be demonstrated by the following relationship:

$$
S_{X Y}=\frac{\sum_{i=1}^{n}\left(x_{i}-\bar{x}\right)\left(y_{i}-\bar{y}\right)}{n}=\frac{\sum_{i=1}^{n} x_{i} y_{i}}{n}-\bar{x} \bar{y}
$$

where:

$S_{X Y}=$ the RFT variable associated with the variable corresponding to NGI-Q values.

The sample size to perform the test is $n=355$. 
The result given by the test is $S_{X Y}=11$, demonstrating the existence of a positive non-linear association between the variables RFT and NGI-Q.

\subsection{Pearson's correlation coefficient $(r)$}

To establish the degree of correlation between the variables RFT and NGI-Q, the Pearson Coefficient is used, the covariances and standard deviations are measured by:

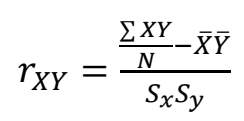

where:

$$
\begin{aligned}
& S_{X Y}>r_{X Y}>0=\text { positive association. } \\
& \mathrm{S}_{X Y}<\mathrm{r}_{X Y}<0=\text { negative association. } \\
& r_{X Y} \approx 0 \quad=\text { absence of association. } \\
& r_{X Y} \approx 1=\text { exact association of positive type. } \\
& r_{X Y} \approx-1=\text { exact association of negative type. }
\end{aligned}
$$

The correlation coefficient takes values between -1 and 1 .

The test gives $r_{X Y}=0.66$ with $S_{X Y}=11$, fulfilling the first condition $S_{X Y}>r_{X Y}>0$ indicating the presence of positive non-linear association.

\subsection{Hypothesis test $r$}

To establish whether the correlation comes from a population whose value is zero, we will establish the following hypotheses:

- $\mathrm{H}_{0}:=0 \mathrm{r}_{\mathrm{XY}}$ The correlation coefficient obtained comes from a population whose correlation is zero $(\rho=0)$.

- $\mathrm{H}_{1}:=0 \mathrm{r}_{\mathrm{XY}}$ The correlation coefficient obtained comes from a population whose correlation coefficient is different from zero $(\rho \neq 0)$.

From the assumption of the null hypothesis $\left(\mathrm{H}_{0}\right)$, we analysed whether the sampling distribution of correlations from a population characterised by a correlation equal to zero $(\rho=0)$ follows a Student's law with $\mathrm{N}-2$ degrees of freedom, with average the population value and standard deviation given by:

$$
S_{r}=\sqrt{\frac{1-r_{x y}^{2}}{N-2}}
$$

where:

$$
\begin{aligned}
& S_{r}=\text { population of samples with correlation equal to zero. } \\
& r_{X Y}=\text { correlation coefficient. } \\
& N \quad=\text { number of samples. }
\end{aligned}
$$

In this scenario, we tried to prove if the correlation coefficient $r_{\mathrm{XY}}$ belongs from samples within the limits of null hypothesis $\left(\mathrm{H}_{0}\right)$.

For practical purposes, the number of standard deviations found in the coefficient obtained from the centre of the distribution is calculated, according to the known formula:

$$
t=\frac{r_{x y}-0}{s_{r}}
$$


Using the t-student table with significance $\alpha$ and N-2 degrees of freedom, the null hypothesis will be accepted or rejected if:

- $\mathrm{t}>\mathrm{t}_{(\alpha, \mathrm{N}-2)}$ : The null hypothesis is rejected. The correlation obtained does not come from a population whose value $\rho_{\mathrm{xy}}=0$. Therefore, the variables are related.

- $t<t_{(\alpha, N-2)}$ : The null hypothesis is accepted. The correlation obtained comes from a population whose value $\rho_{\mathrm{xy}}=0$. Therefore, the variables are not related.

For the variables RFT and NGI-Q, we obtain $\mathrm{t}=16.58$.

Considering a total of data $\mathrm{N}=355$ with significance $\alpha=0.05$, the t-student table gives a value of 1.645 .

The case of $t>t(\alpha, N-2)$ is fulfilled, therefore the null hypothesis is rejected. This means that the variables are related, and the correlation does not come from a population characterised by zero correlation, with a $95 \%$ confidence interval.

\subsection{Confidence intervals of $r$}

As is well known, the Pearson correlation coefficient distribution does not have a normal distribution. For this reason, it is necessary to transform $r$ to obtain a $z$-value that follows a normal distribution (Achen 1982).

This technique is known as Fisher's transformation and calculates the confidence interval of $r$ from $z$. The transformation is:

$$
z=\frac{1}{2} \ln \left(\frac{1+r}{1-r}\right)
$$

The standard error of $\mathrm{z}$ is represented by:

$$
\text { standard error } z=\frac{1}{\sqrt{n-3}}
$$

Where $n$ represents the sample size. The $95 \%$ confidence interval of $z$ is calculated by:

$$
\begin{aligned}
& z_{1}(\text { lower error limit })=z-\frac{1.96}{\sqrt{n-3}} \\
& z_{2}(\text { upper error limit })=z+\frac{1.96}{\sqrt{n-3}}
\end{aligned}
$$

After calculating the confidence intervals with the z-value, it is necessary to perform the inverse process to calculate the intervals of the correlation coefficient $r$ :

$$
\begin{aligned}
& r_{1}(\text { lower correlation limit })=\frac{e^{2 z_{1}}-1}{e^{2 z_{1}+1}} \\
& r_{2}(\text { upper correlation limit })=\frac{e^{2 z_{2}}-1}{e^{2 z_{2}+1}}
\end{aligned}
$$

Using the Fisher transformation, $z=0.79$ is obtained. The lower and upper limits are $z_{1}=0.69$ and $z_{2}=0.90$.

The transformation to the limits of $r$, are $r_{1}=0.60$ and $r_{2}=0.72$.

This means that the confidence intervals of $r=0.66$ are [0.60-0.72] for the correlation between the RFT and NGI-Q.

\section{$5 \quad$ Rock forecast tool as predictor of rock mass quality}

As demonstrated in the previous section, there is a positive non-linear correlation between the RFT model and the rock quality values obtained using NGI-Q.

The non-linear relationship between the RFT and the NGI-Q system can be explained by the difference in the architecture of both models. While the RFT model is made by sums of parameters, the NGI-Q is a multiplicative system. As a matter of fact, the same non-linear characteristic appears in correlation plots 
between RMR (Bieniawski 1989) which is made by sums, and the NGI-Q system (Palmström 2009 for example).

The relationship between both RFT model and NGI-Q comes from a population of data whose correlation is within the limits of $[0.60<r<0.72]$. Consequently, its validity as a model has been demonstrated.

The reliability of the RFT model in its present state is in the same level of the rock mass classification systems as RMR (Bieniawski 1989) and NGI-Q (Norwegian Geotechnical Institute 2015). Knowing the existing limitation in the model, the optimal mathematical form that can be used with a high predictor level to correlate the RFT with the rock quality values was analysed.

The generated predictor uses as a basis a system of gains or losses of geotechnical quality in the unexcavated area, taking advantage of, as an initial reference, the NGI-Q evaluation performed at the starting location of each exploratory borehole.

Figure 13 schematises the initial position of a borehole with known NGI-Q evaluation. From there, every rod of the borehole has a known value of RFT. With these variables solved, it is possible to build a system of gains and losses of rock mass quality in every rod of the borehole.

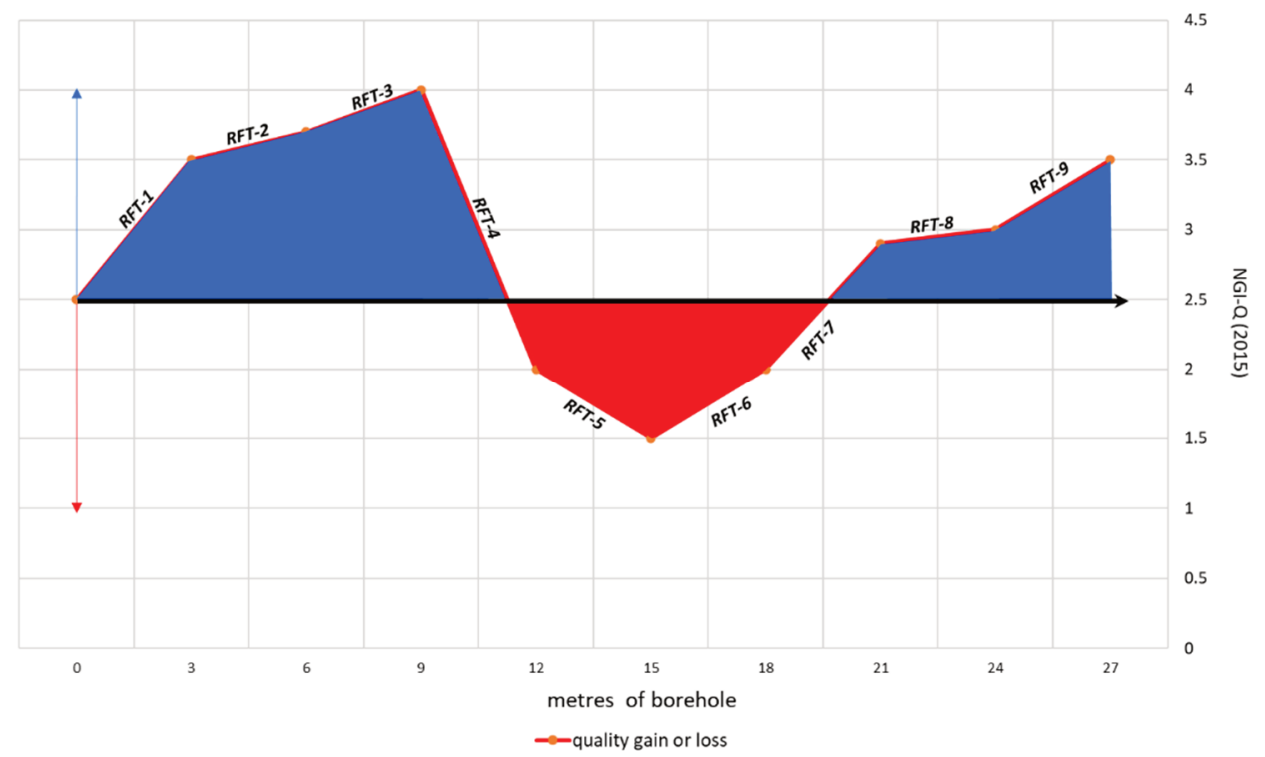

Figure 13 Geotechnical quality gain and loss system through the use of the rock forecast tool model

A practical example of the prediction model is shown in Figure 14. The initial location point of each exploratory borehole has a known geotechnical quality value, which has been evaluated through the geological-geotechnical mapping at the face. Figure 14a shows an excavation advance with known NGI-Q and Figure $14 \mathrm{~b}$ shows the same face of the tunnel with execution of a borehole.

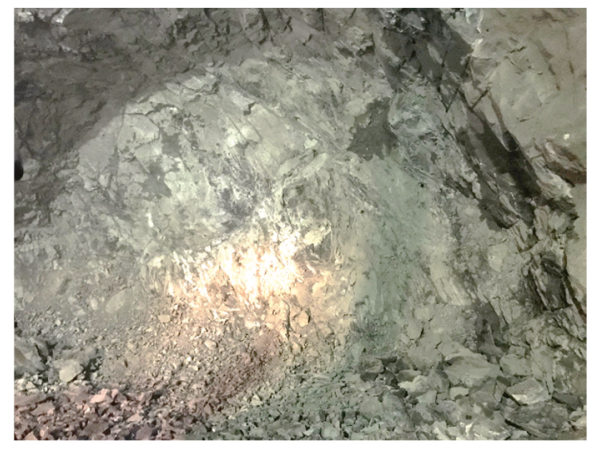

(a)

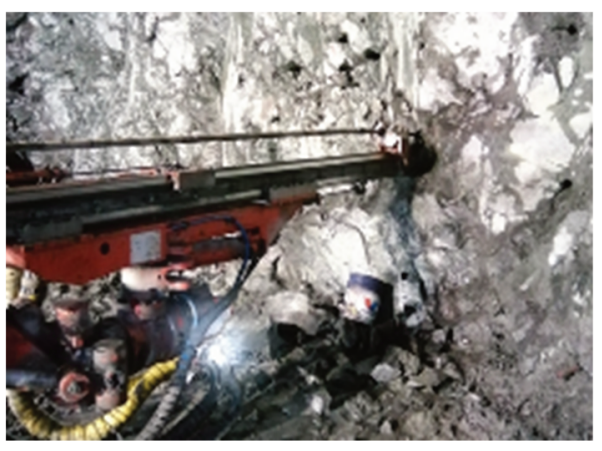

(b)

Figure 14 (a) Excavation progress with NGI-Q geological-geotechnical evaluation; (b) Same advance with subsequent drilling positioning for exploratory borehole with known NGI-Q 
With NGI RFT-Q correlation equation (Equation 2), it is possible to transform the value of NGI-Q of the face to an initial RFT value, that is translated in two ways:

1. If initial RFT is greater than the calculated RFT in borehole rod $n$, then there is a loss of geotechnical quality.

2. If initial RFT is less than the calculated RFT in borehole rod $n$, then there is a geotechnical quality gain.

The model is based on the following equation to quantify the geotechnical quality gains and losses throughout each borehole:

$$
Q_{\text {ROD PREDICTION } n}=Q_{\text {initial }} \times\left(\frac{R F T_{\text {rod } n}}{R F T_{\text {initial }}}\right)^{2}
$$

With the above equation, it is possible to work the results of the predictor model by establishing a range of action for the prediction area handling an oscillation of NGI-Q of $\pm 15 \%$, as shown in Figure 15a. Another option is to use a net prediction, as shown in Figure 15b.

Both cases are real field predictions and correspond to the same borehole, where the prediction of rock quality has been represented in a segmented line, and the NGI-Q value that was subsequently evaluated in excavation progress represented with blue crosses

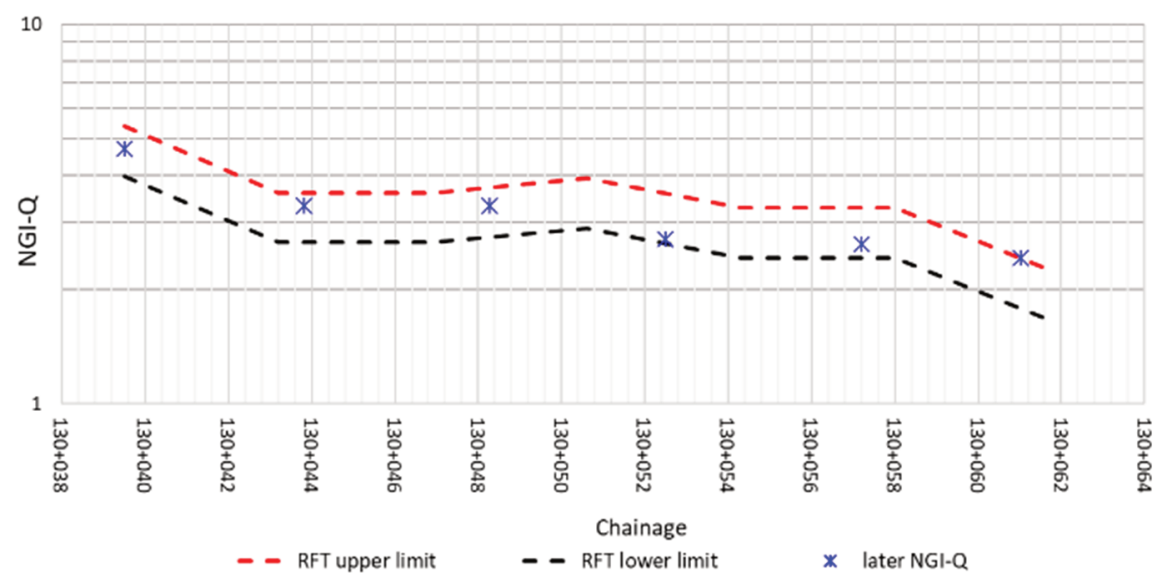

(a)

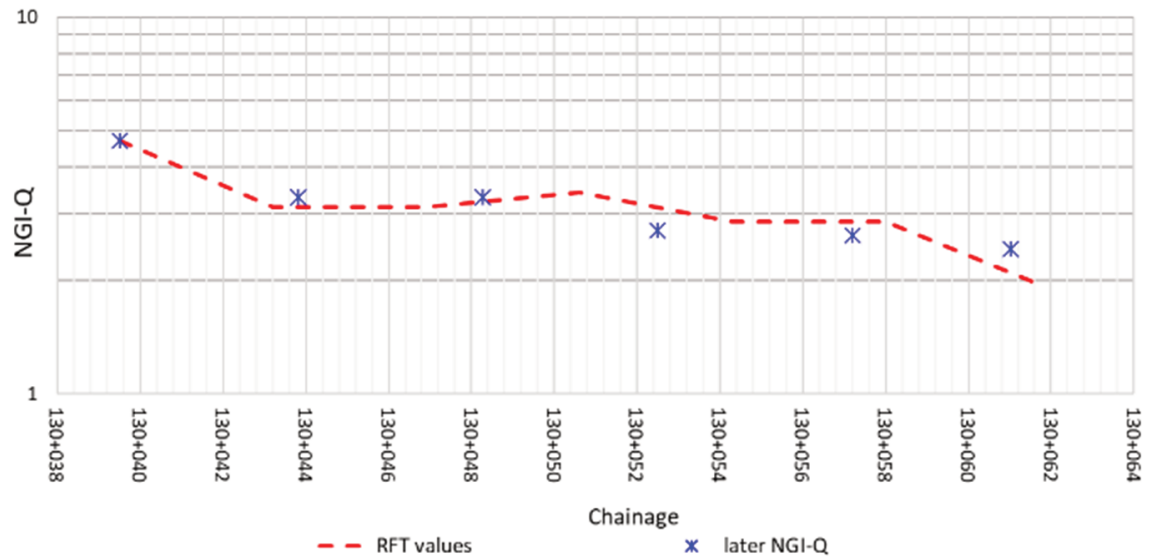

(b)

Figure 15 (a) In segmented lines, the prediction range by rock forecast tool (RFT) is shown and in blue crosses, the NGI-Q values subsequently excavated. (b) Red segmented line shows the net prediction value by RFT and in blue crosses, the NGI-Q values subsequently excavated

At the date of publication of this article, 347 predictions of NGI-Q values have been made, which have been compared to the observed values obtained in the geological and geotechnical evaluations of advances. 
The respective correlation graph, shown in Figure 16, shows a positive linear association that has a coefficient of determination $\mathrm{R}^{2}=0.95$, which is close enough to 1.0 to be able to establish that the reliability of the predictor is high.

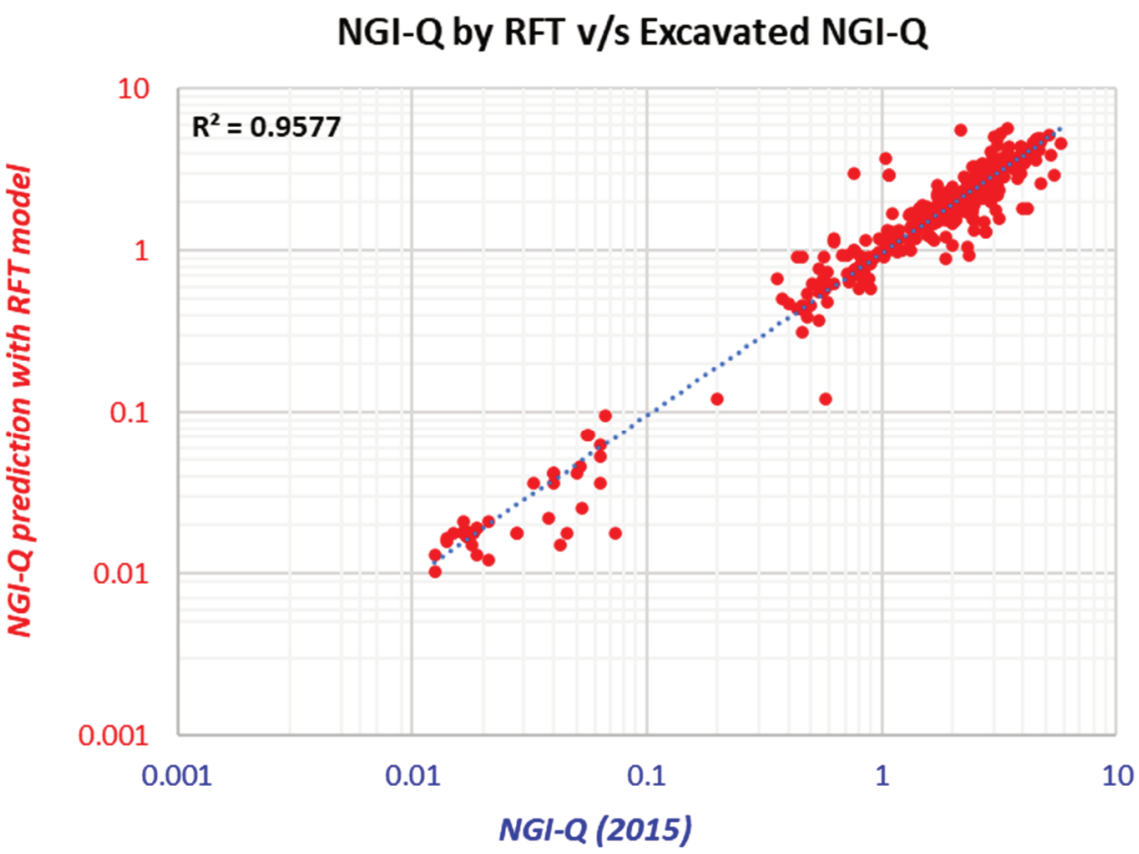

Figure 16 Correlation graph between NGI rock forecast tool-Q predictor and real excavated NGI-Q, with $\mathrm{n}=\mathbf{3 4 7}$

\section{Conclusions and recommendations}

The developed RFT model is a tool in the process of constant development, which uses standardised parameters obtained from the observations of exploratory drillings. The evaluation of the set of parameters forms an index that varies in the range from 5 to 100 and that can be calculated for each rod that is part of an exploratory borehole.

The present study has shown that the RFT has a positive and significant correlation with the evaluated $\mathrm{NGI}-\mathrm{Q}$ values in tunnel advances.

Although its efficiency in all rock mass quality ranges has not yet been proven, it has been shown that the RFT can be used as a rock mass quality prediction system, using as a basis, the latest geotechnical evaluation of the excavation and which, in turn, corresponds to the beginning of the exploratory borehole. The RFT correlation with subsequent Q-NGI face mapping evaluation, is high enough to be used as a reliable tool to make timely constructive decisions in tunnelling.

The RFT used as a predictor proves to have the following virtues:

1. It is possible to develop a rock classification system based on drilling observations and performance. The authors encourage other scientists, construction managers and engineers to go deep in the investigations of the RFT model parameters.

2. The RFT shows significant decreases and/or increases in rock mass quality. It could work by itself without depending on other systems, using technology such as loT monitoring, software and machine learning.

3. It can be used as an early warning system, clearly indicating how far unfavourable sectors are that require special construction measures or different ground support and reinforcement demands. Therefore, it becomes a leading tool for the decisions that the construction team must make. 
The RFT can show changes in the quality ranges, explaining on its own the factors that are responsible for the loss or gain of geotechnical quality.

\section{Acknowledgement}

The authors want to express their gratitude to Company Aura Ingeniería for permitting the investigations and execution of the presented RFT model.

There is a high number of geoscientists, engineers and geologists that provided valuable tips, advice, notes, and reviews to the RFT concept from the very beginning over the past eight years. Just to name a few: mining engineers Raúl Tapia, Matías Toro, Carlos Corvalán; geologists Bárbara Navarro, Rodrigo Farrán, Francisco Eggers, Ernesto Henríquez, Dogan Yalgin, Javier Farías and Andrea Rojas.

To the committee of the Underground Mining Technology and their reviewer's specialists, may you accept the authors gratitude for all the comments and technical reviews for the good of knowledge and excellence.

\section{References}

Achen, $\mathrm{H}$ 1982, Interpreting and Using Regression, Sage, London.

Bieniawski, ZT 1989, Engineering Rock Mass Classifications - A Complete Manual for Engineers and Geologists in Mining, Civil and Petroleum Engineering, Wiley, New York.

Cohen, J \& Cohen, P 1983, Applied Multiple Regression/Correlation Analysis for the Behavioural Sciences, Lawrence Erlbaum Associates, Inc., Hillsdale.

Chungin, L \& Shucai, L 2014, Tunnel Seismic Prediction (TSP) and its application in tunnel engineering, Applied Mechanics and Materials, vol. 501-504, pp. 1779-1782.

Galende, M, Fuente, M, Sainz-Palmero, G \& Menéndez, M 2018, Monitor-while-drilling - based estimation of rock mass rating with computational intelligence: the case of tunnel excavation front, Automation in Construction, vol. 93, pp. 325-338, https://doi.org/10.1016/j.autcon.2018.05.019

Hoek, E \& Brown, ET 1980a, Underground Excavations in Rock, Institution of Mining and Metallurgy, London.

Hoek, E \& Brown, ET 1980b, Empirical strength criterion for rock masses. Journal of the Geotechnical Engineering Division, 106(GT9), pp. 1013-1035.

Hoek, E \& Brown, ET 2018, The Hoek-Brown Failure Criterion and GSI - 2018 Edition, Journal of Rock Mechanics and Geotechnical Engineering, vol. 11, issue 3, pp. 445-463.

Norwegian Geotechnical Institute 2015, Using the Q System, Rock Mass Classification and Support Design, Norwegian Geotechnical Institute, Oslo.

Oraee, K, Mozafari, A, Goodarzi, A \& Oraee-Mirzamani, N 2014, Final wall stability in metal open pit mines using presplit blasting, online presentation, viewed 10 December 2019, https://slideplayer.com/slide/1678947/

Palmström, A 2009, Combining the RMR, Q, and RMi Classification Systems, Tunnelling and Underground Space Technology, vol. 24, issue 4, pp. 491-492.

Pedhazur, J 1997, Multiple Regression in Behavioural Research, 3rd edn. Harcourt Brace, Orlando.

Rivano, S 1993, Leaf Quillota Portillo. National Service of Geology and Mining (SERNAGEOMIN), https://biblioteca.sernageomin.cl/opac/index.asp?param=0\%AD\%88\%92bh\%90\%90r\%5E\&Op=3

Tunnel El Melón II 2018, Internal Reports of Tunnel El Melón II Construction, unpublished. 
